\title{
MEMBANGUN KELOMPOK SADAR WISATA DALAM PENGEMBANGAN POTENSI DESA SEBAGAI DESA WISATA DI DESA CEPAKA KECAMATAN KEDIRI KABUPATEN TABANAN
}

\author{
Ni Made Hartini ${ }^{1 *}$, Ni Made Ernila Junipisa² \\ (Universitas Triatma Mulya ${ }^{\mathbf{1}, \mathbf{2}}$ ) \\ made.hartini@triatmamulya.ac.id ${ }^{*}$
}

\begin{abstract}
Cepaka Village is one of the villages located in the Kediri sub-district, Tabanan Regency. The area has a wide expanse of rice fields and people who are still full of agriculture. The dominant community working in the agricultural and tourism sectors is a village that has the potential to be developed into a tourist village supported by the creative economy. In Community Service Activities in Cepaka Village, Kediri, Tabanan The targets to be achieved are the formation of a Tourism Awareness group as a driver and manager of a tourist village by the local community; Village potentials that have uniqueness and beauty and community creativity can be prepared and packaged as tourist attractions in the development of tourist villages in Cepaka village; The creation of village environmental conditions according to the requirements of a tourist village, namely Sapta Pesona (safe, clean, orderly, beautiful, cool, friendly, and memorable). The method of implementing the PKM program, namely conducting socialization, debriefing and assistance to the Cepaka village community who have awareness of tourism activities. The results achieved in the PKM program are guiding in designing a proposal for the formation of a Tourism Awareness Group submitted by the community with an introduction from the Prebekel to be submitted to the Tabanan Regency Tourism Office. The proposal section consists of the background of developing a tourist village, the potentials to be developed as a tourist village, Vision, Mission and objectives of developing the village as a tourist village. The community is aware of its role and responsibility as a good host for guests or tourists who visit to create a conducive environment and atmosphere as stated in the slogan Sapta Pesona..
\end{abstract}

Keywords: tourism awareness group (pokdarwis), village potential, tourism village.

\section{PENDAHULUAN}

Menurut Undang-Undang No. 10 tahun 2009 tentang Kepariwisataan, Pariwisata adalah "Berbagai macam kegiatan wisata dan didukung fasilitas serta layanan yang disediakan masyarakat setempat. Pariwisata adalah salah satu jenis industry baru yang mampu mempercepat pertumbuhan ekonomi dan penyediaan lapangan kerja, peningkatan penghasilan, standar hidup serta menstimulasi sector-sektor produktif lainnya. Sebagai sector yang komplek, pariwisata juga merealisasikan industry-industri klasik seperti industry kerajinan 
tangan dan cinderamata, penginapan dan transportasi (Yoeti, 1996). Terdapat banyak jenis-jenis wisata yang bisa dikembangkan seperti wisata Alam, wisata budaya, wisata Religi, wisata sejarah, wisata kuliner, dan wisata minat khusus. Desa Cepaka adalah desa perbatasan antara Kabupaten Badung dengan Kabupaten Tabanan merupakan desa yang memiliki potensi untuk dapat dikembangkan menjadi desa wisata yang didukung oleh ekonomi kreatif.

Desa Cepaka adalah desa yang terkecil kedua di Kecamatan Kediri, yang terdiri dari empat banjar (banjar adalah istilah lain dari rukun warga /RW). Pusat data DUKCAPIL Kabupaten Tabanan tahun 2019 menunjukkan bahwa penduduk desa Cepaka berjumlah 2.326 jiwa terbagi dalam 698 KK. Profil penduduk dilihat dari usia didominasi oleh warga yang berusia antara 26-56 tahun; sebanyak 1.093; artinya $47 \%$ penduduk adalah usia pekerja aktif. Dari perspektif agama, penduduk desa Cepaka dominan menganut agama Hindu. Tingkat pendidikan masyarakat rata-rata adalah SMU, SMP dan SD. Sebagian besar warga Desa Cepaka berprofesi sebagai karyawan swasta yakni 462 orang (42\%), berwirausaha 179 orang $(16 \%)$, dan 135 orang (12\%) sebagai buruh harian.

Masyarakat desa Cepaka dominan bekerja pada sektor pertanian dan pariwisata. Struktur tanah yang subur dengan sawah yang hijau memberi kesempatan kepada petani untuk mengelola sawah dengan baik sehingga hasilnya optimal. Hamparan sawah dan keindahan desa ini dapat menjadi potensi untuk dikembangkan sebagai destinasi wisata. Selain karena alamnya yang masih asri dan penduduk di Desa Cepaka mayoritas bekerja sebagai petani, akses menuju Desa Cepaka juga cukup memadai. Jarak Bandara Internasional I Gusti Ngurah Rai menuju Desa Cepaka sejauh 24 Kilometer yang dapat ditempuh selama kurang lebih 45 menit saja. Selain bekerja sebagai petani penduduk Desa Cepaka juga memiliki beragam usaha kecil seperti kuliner Babi Guling, budidaya Jamur, Seni Ukiran kayu serta pengolahan kayu dan pembuatan Dupa. Di desa Cepaka terdapat Jogging Track, Bendungan serta Terowongan Bawah Tanah peninggalan masa penjajahan Belanda. Potensi tersebut dapat dikelola dan dikembangkan menjadi daya tarik wisata. Saat ini, pengelolaan dan pengembangan potensi yang ada belum digarap oleh masyarakat setempat karena keterbatasan pengetahuan dan pemahaman tentang kegiatan kepariwisataan dan pengelolaan atas potensi-potensi yang memiliki peluang yang mengarah pada kesejahteraan masyarakat. Oleh karena itu dibutuhkan sosialisasi dan pendampingan kepada masyarakat untuk dapat menggali, mengelola serta memanfaatkan peluang yang ada sebagai daya penggerak perekonomian, sehingga masyarakat menjadi masyarakat yang produktif, kreatif, dan mandiri secara ekonomi.

Pada perkembangan saat ini, di desa Cepaka, beberapa dari masyarakat menerima kunjungan masyarakat luar yang ingin bersepada atau jogging dilahan pertanian pada pematang sawah yang membentang luas sebagai jalur jogging trac sambil berselfie swafoto menikmati indah nan hijau pemandangan alam desa. Ada juga yang sengaja berkunjung ke petani jamur untuk melihat proses budi daya jamur, mengunjungi tempat 
ukiran kayu serta menikmati kuliner khas desa Cepaka yaitu, masakan Babi Guling yang menjadi primadona masyarkat Bali. Situasi tersebut perlu mendapatkan perhatian untuk dibina dan dikelola dengan mengajak masyarakat desa agar memanfaatkan peluang yang ada dengan membentuk kelompok sadar wisata yang disingkat menjadi Pokdarwis. Kelompok sadar wisata merupakan kelompok yang anggotanya dipilih dari masyarakat dan oleh masyarakat itu sendiri yang memiliki kesadaran terhadap lingkungan agar pengembangan desa sebagai desa wisata dapat tercapai. Dalam pembentukanPokdarwis dibutuhkan pendampingan dari berbagai pakar disiplin ilmu khususnya kepariwisataan serta kewirusahaan agar apa yang menjadi permasalahan desa dalam mengembangkan potensi-potensi yang ada dapat dicarikan jalan keluarnya untuk mencapai tujuan yaitu masyarakat produktif dan mandiri secara ekonomi yang berasaskan budaya dan kearifan lokal.

\section{METODE PELAKSANAAN}

Berdasarkan uraian permasalahan pada program PKM, maka prioritas pelaksanaan program dilaksanakan, yaitu mengadakan sosialisasi, pembekalan dan pendampingan kepada masyarakat desa Cepaka yang memiliki kesadaran terhadap kegiatan kepariwisataan. Masyarakat desa Cepaka yang terdiri atas masyarakat 4 (empat) Banjar Dinas yang dapat digerakkan, dipilih untuk dibentuk sebagai kelompok sadar wisata sesuai bidang, bakat serta minat yang dimilikinya. Memberikan sosialisasi serta pembekalan tentang Desa Wisata dan Sadar Wisata yang merupakan konsep yang menggambarkan partisipasi dan dukungan segenap komponen masyarakat dalam mendorong terwujudnya iklim yang kondusif bagi tumbuh dan berkembangnya kepariwisataan disuatu wilayah dan untuk meningkatkan kesejahteraan rakyat.

Melakukan pendataan dan penataan terhadap jalur yang dapat dijadikan areal Jogging (Jogging track), karena luasnya lahan persawahan yang asri serta pematang sawah yang telah dipasang batu paving sangat layak untuk dikemas menjadi areal tracking, baik dengan bersepada ria, maupun jogging atau jalan santai sambil menikmati segarnya udara dan indahnya panorama sawah nan hijau membentang luas, dikelilingi paritparit kecil dengan suara air mengalir jernih. Memberikan pembinaan dan pembekalan kewirausahaan terkait usaha-usaha kecil, mikro dan menengah yang dimiliki masyarakat desa agar dapat bersinergi untuk memenuhi kebutuhan akan komunikasi, konsumsi serta kebutuhan lain seperti oleh-oleh khas desa atau cindramata. Kewirausahaan dalam hal ini diberikan pembekalan tentang manajemen bisnis agar sesuai dengan prinsip-prinsip berwirausaha serta menangkap peluang dalam bersinergi dengan konsep desa wisata.

\section{HASIL DAN PEMBAHASAN}

Dalam pelaksanaan kegiatan Pengabdian Kepada Masyarakat di desa Cepaka, Kediri, Tabanan adalah dengan memberikan sosialisasi dan pembekalan dalam membentuk Kelompok Sadar Wisata yang diawali dengan menyusun proposal Pembentukan Kelompok Sadar Wisata yang diajukan oleh masyarakat dengan pengantar dari Prebekel atau Kepala 
Desa ke Dinas Pariwisata Kabupaten Tabanan. Bagian proposal yang terdiri dari latar belakang pengembangan desa wisata, potensi-potensi yang dikembangkan sebagai daya tarik desa wisata, Visi, Misi dan tujuan pengembangan desa wisata, masyarakat yang ditunjuk dan mau sebagai pengelola desa wisata dengan membentuk struktur organanisasi Kelompok Sadar Wisata, serta fotofoto pendukung objek yang dijadikan daya tarik desa wisata. Merujuk pada profil desa, masyarakat desa Cepaka yang didominasi oleh usia produktif yang banyak bekerja pada sector pertanian dan pariwisata merupakan factor yang sangat mendukung untuk dibentuknya kelompok Sadar Wisata. Peran ibu-ibu PKK, Teruna-teruni desa juga dapat diberdayakan sebagai penggerak dalam kelompok sadar wisata.

Masyarakat sebagai kelompok sadar wisata yang mengelola desa wisata berperan aktif dalam 2 hal sebagai berikut: a) Masyarakat menyadari peran dan tanggung jawabnya sebagai tuan rumah (Host) yang baik bagi tamu atau wisatawan yang berkunjung untuk mewujudkan lingkungan dan suasana yang kondusif sebagaimana yang tertuang dalam slogan Sapta Pesona. b) Masyarakat menyadari hak dan kebutuhannya untuk menjadi pelaku wisata atau wisatawan untuk melakukan perjalanan kesuatu wilayah tujuan wisata sebagai wujud dasar untuk berekreasi maupun khususnya dalam mengenal dan mencintai tanah air. c) Kelompok Sadar Wisata (Pokdarwis) atau Kelompok Penggerak pariwisata sebagai bentuk kelembagaan informal yang dibentuk anggota masyarakat (khususnya yang memiliki kepedulian dalam mengembangkan kepariwisataan didaerahnya), merupakan salah satu unsur pemangku kepentingan dalam masyarakat yang memiliki keterkaitan dan peran penting dalam mengembangkan dan mewujudkan sadar wisata dan Sapta Pesona di daerahnya.

Pemberdayaan Masyarakat dalam konteks pembangunan kepariwisataan dapat didefinisikan sebagai: "Upaya penguatan dan peningkatan kapasitas, peran dan inisiatif masyarakat sebagai salah satu pemangku kepentingan, untuk dapat berpartisipasi dan berperan aktif sebagai subjekatau pelaku maup un sebagai penerima manfaat dalam pengembangan kepariwisataan secara berkelanjutan". (Renstra Dit.Pemberdayaan Masyarakat, 2010). Pendampingan kepada masyarakat yang sadar terhadap peran pariwisata untuk meningkatkan produktifitas mendapatkan pemahaman dan pengetahuan yang berkenaan dalam hal-hal sebagai berikut: 1) bahwa Desa Wisata dan Sadar Wisata yang merupakan konsep yang menggambarkan partisipasi dan dukungan segenap komponen masyarakat dalam mendorong terwujudnya iklim yang kondusif bagi tumbuh dan berkembangnya kepariwisataan disuatu wilayah dan untuk meningkatkan kesejahteraan rakyat. Berdasrkan Undang-undang No. 10 Tahun 2010, yaitu tujuan membangun Pariwisata. 2) Mendata dan penataan terhadap jalur yang dapat dijadikan areal Jogging (Jogging track), karena luasnya lahan persawahan yang asri serta pematang sawah yang telah dipasang batu paving sangat layak untuk dikemas menjadi areal tracking, baik dengan bersepada ria, maupun jogging atau jalan santai sambil menikmati segarnya udara dan 
indahnya panorama sawah nan hijau membentang luas, dikelilingi paritparit kecil dengan suara air mengalir jernih. 3) Pembinaan dan pembekalan kewirausahaan terkait usaha-usaha kecil, mikro dan menengah yang dimiliki masyarakat desa agar dapat bersinergi untuk memenuhi kebutuhan akan komunikasi, konsumsi serta kebutuhan lain seperti oleh-oleh khas desa atau cindramata. Kewirausahaan dalam hal ini diberikan pembekalan tentang manajemen bisnis agar sesuai dengan prinsip-prinsip berwirausaha serta menangkap peluang dalam bersinergi dengan konsep desa wisata.

4) Sebagai desa wisata tentunya ada objek yang menjadi ciri khas desa tersebut. Salah satu dari objek yang unik dan menarik adalah adanya terowongan bawah tanah peninggalan jaman penjajahan Belanda yang dibuat untuk bendungan. Potensi terowongan bersejarah ini diangkat kembali sebagai situs bersejarah dengan menata, mengecek keamanan, serta mengangkat nilai-nilai sejarah yang dihadirkan dalam desa wisata. 5) Sebagai penggerak dan pengelola desa wisata harus ada organisasi atau badan yang menangani serta yang bertanggung jawab atas terselenggaranya kegiatan kepariwisataan. Dengan didukung dan difasilitasi oleh kepala desa beserta staf, masyarakat diberikan sosialisasi, pembinaan dan pemebakalan terkait pembentukan Pokdarwis Desa Cepaka sebagai pengelolanya. Pokdarwis yang dibentuk terdiri dari lapisan masyarakat desa Cepaka yang terdiri dari unsur teruna-teruni desa, ibu-ibu PKK, serta masyarakat yang mau dan sadar terhadap potensi desa wisata menjadi desa yang maju, berbudaya, mandiri serta sejahtera.

\section{KESIMPULAN}

Pelaksanaan

Pengabdian

Kepada Masyarakat di Desa Cepaka Kecamatan Kediri, Kabupaten Tabanan adalah berjalan sesuai dengan rencana kegiatan dalam pembentukan Kelompok Sadar Wisata sebagai pengolala desa Wisata dan menggali potensi desa sebagai daya Tarik wisata. Adapun hal-hal yang telah diterlaksana adalah sebagai berikut: 1) Tersusunnya proposal pembentukan Kelompok Sadar Wisata sebagai dasar permohonan terbentuknya Pokdarwis pada pengelolaan desa Wisata di desa Cepaka, Kecamatan Kediri, Tabanan. 2) Masyarakat desa Cepaka telah mempersiapkan potensi-potensi wisata seperti areal hamparan persawahan yang membentang luas telah ditata dengan menggunakan batu paving pada pematang sawah sebagai tempat tracking dan jogging, terowongan bawah tanah dan DAM peninggalan zaman penjajahan Belanda sebagai daya Tarik wisata sejarah, berbagai kerajinan kayu, dan home industry serta budi daya jamur dan wisata kuliner babi Guling Selingsing yang sangat khas desa Cepaka. Potensi-potensi tersebut merupakan daya Tarik wisata untuk kebutuhan industry kepariwisataan yang dikemas dalam paket desa wisata. 3) Masyarakat desa Cepaka telah mempersiapkan diri dan memiliki kepedulian terhadap lingkungan guna menunjang aktivitas kepariwisataan pada konsep desa wisata yang merupakan syarat terpenuhinya unsur-unsur Sapta Pesona.

Sesuai dengan apa yang telah dihasilkan dalam pengabdian kepada masyarakat di desa Cepaka, Kediri Tabanan, maka adapun saran yang dapat disumbangkan dalam kegiatan 
ini adalah sebagai berikut: 1) Dengan telah diajukannya proposal pembentukkan Pokdarwis (Kelompok Sadar Wisata) ke Dinas Pariwisata Kabupaten Tabanan oleh Kepala Desa Cepaka, diharapkan masyarakat yang menjadi bagian dari Pokdarwis nantinya selalu berkomitmen menjalankan tugas-tugas sebagai pengelola desa wisata sesuia dengan visi, misi serta tujuan untuk menciptakan desa yang maju, produktif, dan mandiri secara ekonomi sehingga tercapainya kesejahteraan masyarakat. 2) Poteni-potensi desa lainnya yang belum digarap, yang memiliki potensi besar dalam kegiatan kepariwisataan seperti kerawitan, kegiatan kesenian, dan usaha kreatif lainnya dapat dikemas dalam produk wisata minat khusus untuk menambah lini produk wisata desa Cepaka, sehingga desa Cepaka memiliki beragam produk desa wisata yang mampu menarik minat wisatawan untuk berkunjung ke desa tersebut. 3) Diharapkan seluruh masyarakat desa Cepaka senantiasa menjaga lingkungan desa yang aman, tertib, bersih, indah, ramah, sejuk, sehingga setiap wisatawan yang datang berkunjung akan senantiasa memiliki kenangan tak terlupakan ketika berada di desa Cepaka dan hal tersebut akan menjadi bagian dari promosi secara tidak langsung melalui word of Mouth atau mereka yang pernah datang merekomendasikan pengalamannya kepada rekan mereka untuk datang berkunjung ke desa Cepaka.

\section{UCAPAN TERIMA KASIH}

Puji syukur kami panjatkan kepada Tuhan Yang Maha Esa/Ida Sang Hyang Widhi Wasa atas kasih dan penyertaan-Nya sehingga kami dapat melaksanakan Pengabdian
Kepada Masyarakat (PKM) di Desa Cepaka dapat terlaksana dengan baik. Pelaksanaan Pengabdian Kepada Masyarakat yang dilaksanakan selama satu bulan di Desa Cepaka, Kecamatan Kediri, Kabupaten Tabanan merupakan bagian dari Tri Dharma Perguruan Tinggi selain pengajaran dan penelitian. Pelaksanaan Pengabdian ini tidak terlepas dari bantuan pihakpihak yang telah meluangkan waktu, tenaga serta pemikiran yang menjadi tujuan pengabdian ini. Oleh karena itu, kami menyampaikan terimakasih kepada: Bapak Dr. I Ketut Putra Suarthana, MM, selaku Rektor Universitas Triatma Mulya. Bapak Dr. Ida Ketut Kusumawijaya, SE, MM, selaku Ketua Lembaga Penelitian dan Pengabdian Masyarakat (LPPM) Universitas Triatma Mulya. Bapak Dr. I Nengah Aristana, SE,.MM, selaku Dekan Fakultas Bisnis dan Sosial Humaniora Universitas Triatma Mulya. Bapak I Made Hedi Wartana, SE., MM selaku Kepala Bagian Pengabdian Kepada Masyarakat Universitas Triatma Mulya Bapak/ibu rekan-rekan dosen yang telah membantu terlaksananya program Pengabdian Kepada Masyarakat dalam menyumbangkan waktu, tenaga, serta pikiran hingga laporan PKM dapat diselesaikan. Drs. I Ketut Teja, selaku Kepala Desa Cepaka, Kecamatan Kediri, Kabupaten Tabanan. Bapak Wayan Wije, selaku Bandesa Adat Desa Cepaka, Kecamatan Kediri, Kabupaten Tabanan. Masyarakat Desa Cepaka yang telah menerima kami dan banyak membantu serta bekerjasama selama pelaksanaan PKM. Staf akademik serta adik-adik mahasiswa yang banyak membantu terlaksananya PKM ini. 
Laporan ini masih jauh dari sempurna, oleh karena itu sangat diharapkan kritik dan saran yang membangun demi kesempurnaan laporan Pengabdian Kepada Masyarakat di Desa Cepaka dengan Judul Membangun Kelompok Sadar Wisata Dalam Pengembangan Potensi Desa Sebagai Desa Wisata Di Desa Cepaka, Kecamatan Kediri Kabupaten Tabanan. Semoga laporan ini dapat bermanfaat bagi pembaca.

\section{DAFTAR PUSTAKA}

Hartini., Wisnawa. (2020). Sinergi Masyarakat Dalam Mengelola Potensi Desa Sebagai Desa Wisata Budaya Di Desa Pekraman Pemanis, Biaung, Kecamatan Penebel, Kabupaen Tabanan, Bali. Jurnal Aplikasi Iptek (Paradharma). Volume 4 No. 2. Undhira. Badung.

Karini, Marcos, Indah. (2018). Kelompok Sadar Wisata (Pokdarwis) Desa Wisata Limbasari Kecamatan Bobot Sari Kabupaten Purbalingga. Jurnal Pengabdian Masyarakat (J-ABDIPAMAS). Vol. 2 No. 2 IKIP PGRI. Bojonogoro.

Mustofa, Ahda. (2017). Pengembanga Desa Wisata Bangun Cipto. Jurnal Pemberdayaan. Vol. 2. No. 1. Universitas Ahmad Dahlan. Yogyakarta.

Rahim, Firmansyah. (2011). Pedoman Kelompok Sadar Wisata. Direktur Jenderal Pengembangan Destinasi Pariwisata Kementerian Pariwisata dan Ekonomi Kreatif. Jakarta.
Rahmawati, Sunarti, Hakim. (2017). Penerapan Sapta PESONA Pada Desa Wisata (Analisis Persepsi Wisataan Atas Layanan Penyedia Jasa di Kampun Wisata Kungkuk Desa Punten Kota Batu. Jurnal Administrasi Bisnis (JAB). Vol. 50. No. 2. Brawijaya. Surabaya.

Wisnawa, dkk. (2019). Manajemen Pemasaran Pariwisata: Model Brand Loyalty Pengembangan Potensi Wisata Di Kawasan Pedesaan. Cetakan I. IKAPI. Yogyakarta.

Yoety, Oka. (1996). Pengantar Ilmu Pariwisata. Angkasa. Bandung 